07

\title{
Локализация прохождения тока в термофотовольтаических преобразователях на основе двойных гетероструктур InAsSbP/InAs
}

\author{
() Б.А. Матвеев, ${ }^{1,2}$ В.И. Ратушный, ${ }^{3}$ А.Ю. Рыбальченко 3 \\ ${ }^{1}$ Физико-технический институт им. А.Ф. Иофрфе РАН, \\ 194021 Санкт-Петербург, Россия \\ ${ }^{2}$ ООО „ИофрфеЛЕД“, \\ 194064 Санкт-Петербург, Россия \\ ${ }^{3}$ Волгодонский инженерно-технический институт - фрилиал Национального исследовательского \\ ядерного университета МИФИ, \\ 347360 Волгодонск, Россия \\ e-mail: ioffeled@mail.ru
}

Поступило в Редакцию 17 января 2019 г.

В окончательной редакции 7 мая 2019 г.

Принято к публикации 13 ноября 2019 г.

\begin{abstract}
Исследованы основные электрические характеристики термофотовольтаических преобразователей, выполненных на основе двойных гетероструктур $p$-InAsSbP/n-InAs $/ n$-InAsSbP с полностью либо частично удаленной подложкой в конструкции флип-чип. Показано влияние сопротивления разных частей структуры на пространственное распределение плотности тока в активной области, и определены условия для получения максимально эффективного сбора фототока/минимального сгущения линий тока.
\end{abstract}

Ключевые слова: термофотовольтаический преобразователь, гетероструктуры InAsSbP/InAs, вольтамперные характеристики, распределение плотности тока.

DOI: 10.21883/JTF.2020.05.49187.14-19

\section{Введение}

Гетероструктуры (ГС), содержащие, по крайней мере один гетеропереход InAsSbP/InAs, широко используются для изготовления диодных лазеров, свето- и фотодиодов, работающих в области длин волн $3-3.6 \mu \mathrm{m}$. На их основе изготовлены сенсоры для проведения научных $[1,2]$ и медицинских [3] исследований, для анализа газовой среды, содержащей углеводороды $[4,5]$, а также для дистанционных измерений температуры [6,7]. Благодаря малой ширине запрещенной зоны InAs $(0.35 \mathrm{eV}$ при температуре $300 \mathrm{~K}$ ) данные ГС перспективны и для создания термофотовольтаических преобразователей (ТФВП), генерирующих электрическую энергию за счет поглощения теплового излучения нагретых тел с температурой ниже $1000^{\circ} \mathrm{C}[8-11]$.

В литературе имеется существенный разброс в значениях последовательного сопротивления и в других параметрах вольт-амперных характеристик (BAX) ГС $p$-InAsSbP/n-InAs (см., например, [5,10,12,13]), но, к сожалению, обычно эти параметры не сопоставляются с особенностями конструкции ГС, например, с геометрией контактов и/или с наличием или отсутствием в ГС подложки, что не позволяет в полной мере оценить применимость последних в ТФВП.

В [11] было показано, что для создания эффективных ТФВП на основе ГC InAsSbP/InAs необходимо одновременно уменьшать тепловое сопротивление между активной областью структуры и теплоотводом и расширять спектр фоточувствительности в область коротких длин волн. В работе [14] последнее достигается за счет удаления подложки $n$-InAs в структурах типа флип-чип. Естественно предположить, что при удалении подложки существенным образом изменяются значения сопротивлений различных областей структуры, что может привести к снижению эффективности сбора фототока, например, из-за пространственной локализации его прохождения [15]. Поэтому важной задачей разработки эффективных ТФВП на основе двойных ГС (ДГC) InAsSbP/InAs является исследование BAX и пространственного распределения плотности тока во флипчип диодах, имеющих различные варианты конструкции и подключения чипов к внешнему источнику смещения/нагрузке.

\section{Образцы и методики измерений}

В настоящей работе изучались изопериодные ДГС, выращенные методом жидкофазной эпитаксии на сильно легированных подложках $n^{+}-\mathrm{InAs}(\mathrm{Sn}) \quad\left(n^{+}=\right.$ $\left.=(2-3) \cdot 10^{18} \mathrm{~cm}^{-3}\right)$ и содержащие нелегированный широкозонный слой $n$-InAsSbP толщиной $2-3 \mu \mathrm{m}$, активную область (АО) из $n$-InAs толщиной $7-8 \mu \mathrm{m}$ и контактный широкозонный слой $p$-InAsSbP толщиной $2-3 \mu \mathrm{m}$, аналогично описанным нами ранее [16]. На рис. 1 приведены спектры фотолюминесценции (ФЛ), измеренные в „отраженных лучах“ со стороны $p$-InAsSbP и $n$-InAsSbP при $77 \mathrm{~K}$. В последнем случае измерения проводились на специально выращенном 


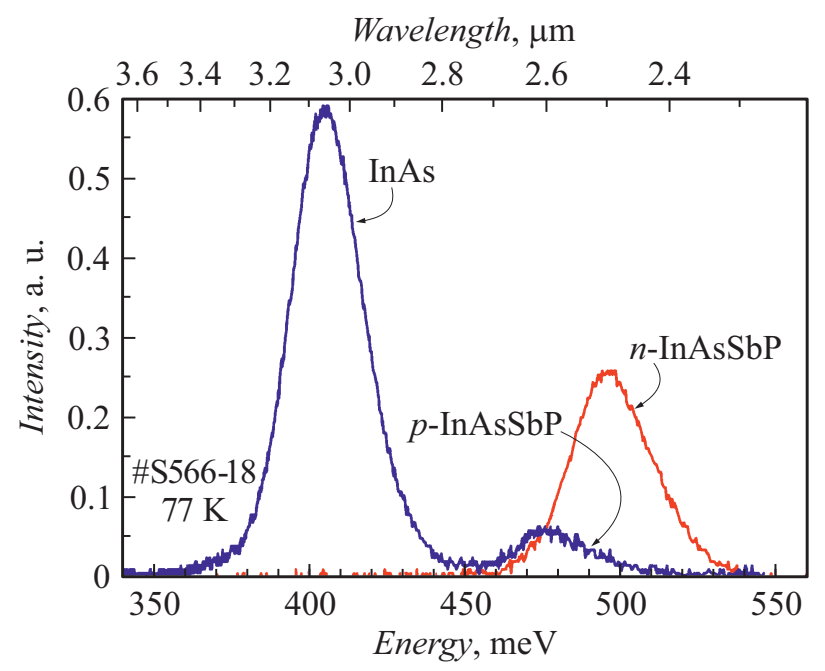

Рис. 1. Спектры ФЛ ГС $p$-InAsSbP $/ n$-InAs $/ n-\operatorname{InAsSbP} / n^{+}$-InAs.

$a$

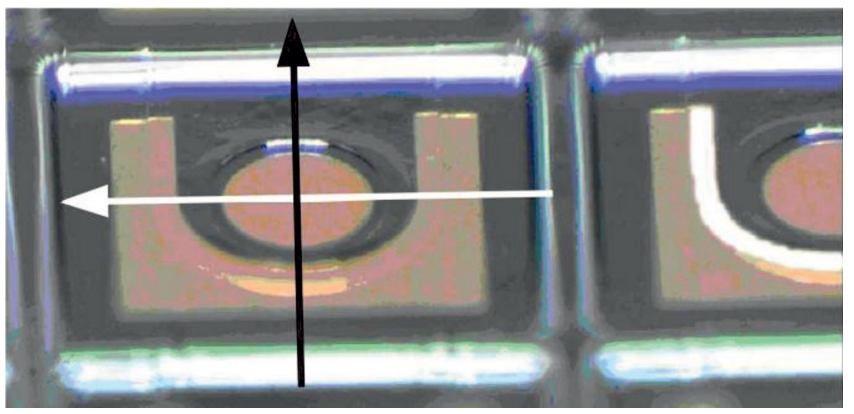

$b$

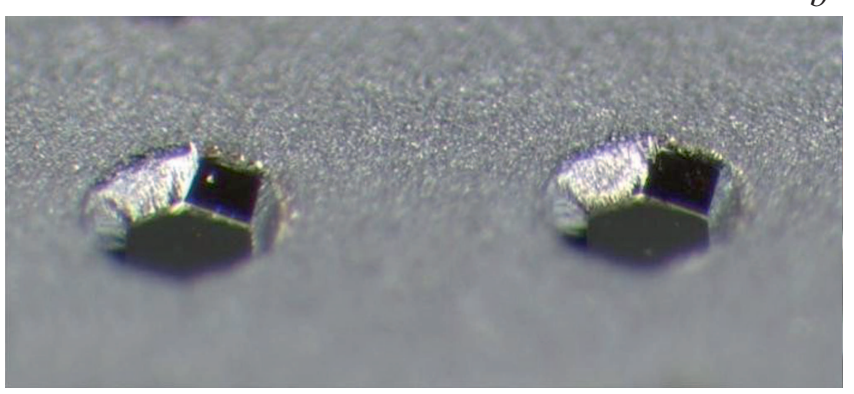

Рис. 2. $a-$ фотография эпитаксиальной стороны ДГС с двумя неразделенными чипами диодов, имеющих круглый анод и $U$-образный катод. На левом чипе обозначены направления симметричного (черная стрелка) и несимметричного (белая стрелка) сечений. На правом чипе белым цветом также выделена $U$-образная область катода, в которой металл сопрягался со слоем $n$-InAs; $b-$ фотография подложечной поверхности неразделенных чипов с находящимися на ней глухими отверстиями. Дно отверстий - слой $n$-InAsSbP, однородный фон поверхность $n^{+}$-InAs.

образце-,спутнике“, представлявшем собой ГС $n$-InAsSbP $/ n^{+}$-InAs. Наблюдаемое несовпадение пиков ФЛ, обусловленных рекомбинацией носителей заряда в слоях $p$-InAsSbP и $n$-InAsSbP, может быть вызвано участием в рекомбинации носителей на уровнях акцепторной примеси, находящихся на $\sim 15 \mathrm{meV}$ выше потолка валентной зоны в $p$-InAsSbP.

Слой $p$-InAsSbP создает на границе с AO потенциальный барьер для неравновесных электронов. Слой $n$-InAsSbP создает потенциальный барьер для неравновесных дырок, для которых диффузионная длина в нелегированном $n$-InAs составляет $10-20 \mu \mathrm{m}$ [17], а также служит „широкозонным окном“ для падающего потока фотонов в структурах с удаленной подложкой.

Методы и установки для проведения измерений описаны нами ранее в [16]. Основные отличия от прежних образцов в [16] состояли в том, что: а) высота мезы составляла $5-8 \mu \mathrm{m}$, что позволяло отнести мезу к разряду „мелких мез“; б) катод толщиной $2 \mu \mathrm{m}$, состоящий из последовательности металлов $\mathrm{Cr}-\mathrm{Au}-\mathrm{Ni}-\mathrm{Au}$, был выполнен в виде буквы $U$ (или ,подковы“), и был сопряжен как со слоем $p$-InAsSbP, так и со слоем $n$-InAs (рис. 2,a), что позволяло производить монтаж диода по
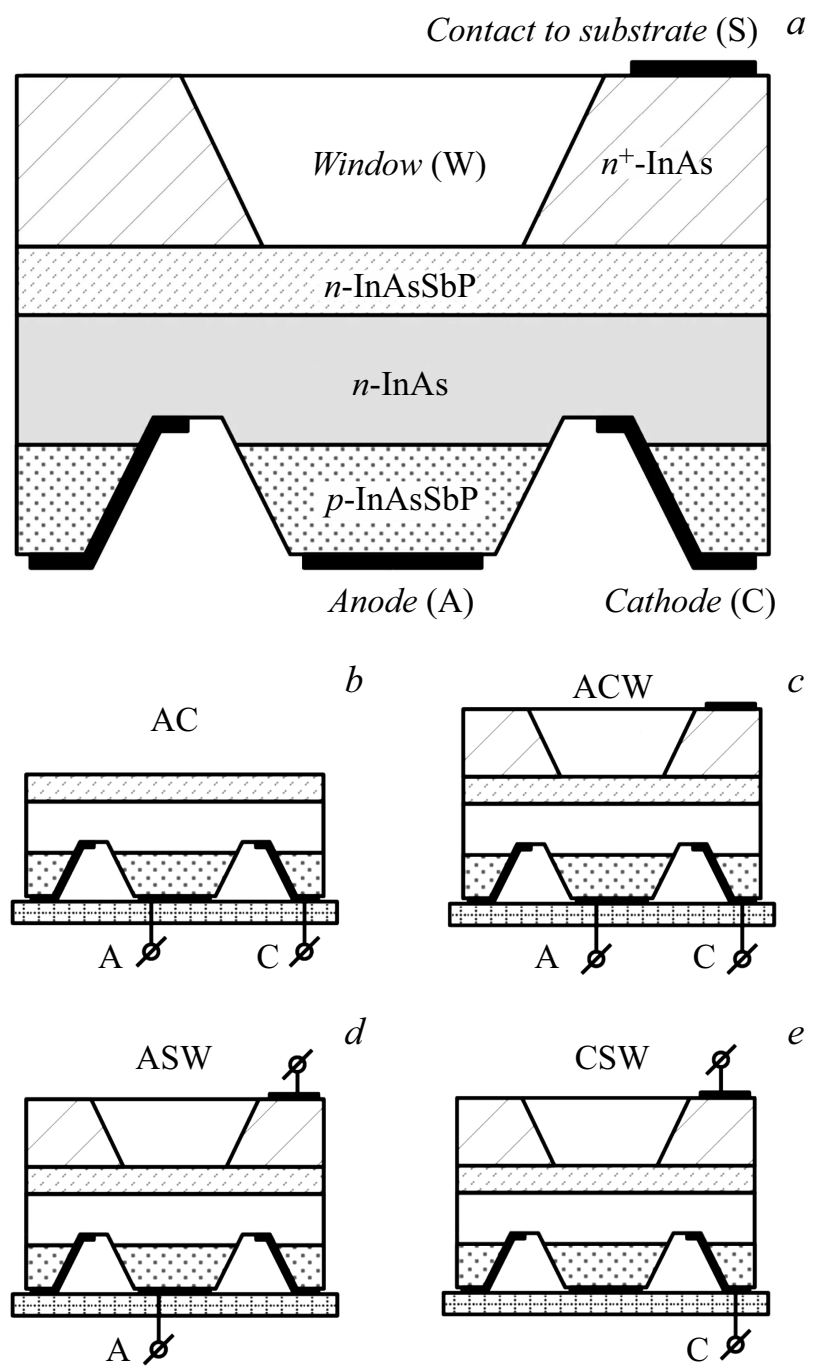

Рис. 3. Схема чипа с частично удаленной подложкой $(a)$, варианты подключения чипов к источнику напряжения смещения $(b-e)$. 
методу флип-чип; в) подложка $n^{+}-\mathrm{InAs}$, имевшая начальную толщину $400 \mu \mathrm{m}$, перед измерениями либо частично, либо полностью удалялась. Меза в виде усеченного конуса имела диаметр в плоской части $300 \mu \mathrm{m} \mathrm{c}$ расположенным на ней дисковым анодом диаметром $260 \mu \mathrm{m}$ и толщиной $2 \mu \mathrm{m}$, выполненным из последовательности металлов $\mathrm{Cr}-\mathrm{Au}-\mathrm{Ni}-\mathrm{Au}$. Соотношение площадей области катода, сопряженной с $\mathrm{AO} n$-InAs (выделена на рис. 2, а на правом чипе), анода и области катода, сопряженной с $p$-InAsSbP, составляло $1: 2.3: 5.7$. При частичном удалении $n^{+}-$InAs в области, примыкающей к мезе, образованное глухое отверстие в подложке имело форму усеченной шестигранной пирамиды, у основания которой находилась поверхность слоя $n$-InAsSbP (рис. 2,b). В диодах с частично удаленной подложкой последняя снабжалась дополнительным омическим контактом, что давало возможность подавать смещение на различные части образца и тем самым изменять путь протекания тока в ГС. На рис. 3 представлены схемы структуры и расположения контактов для чипа с частично удаленной подложкой $(a)$ и варианты подключения проводников/подачи смещения к чипам $(b-e)$.

\section{Результаты измерений и их обсуждение}

Из прямых ветвей ВАХ определялись ток насыщения $I_{\text {sat }}$, фактор идеальности $\beta$ и последовательное сопротивление $R_{S}$ путем аппроксимации функциями вида:

$$
U=\frac{\beta k T}{e} \ln \left(\frac{I}{I_{\mathrm{sat}}}+1\right)+I R_{s},
$$

где $k-$ постоянная Больцмана, $T-$ абсолютная температура, $e$ - заряд электрона. С учетом полученных значений $R_{s}$ определялось суммарное падение напряжения на потенциальных барьерах $\left(U_{b}\right)$ :

$$
U_{b}=U-I R_{s} .
$$

Для линейных участков ВАХ при больших прямых токах, помимо значения $R_{s}$, определялось также напряже-

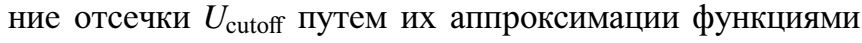
вида

$$
I=\left(U-U_{\text {cutoff }}\right) / R_{s} .
$$

На рис. 4 приведены ВАХ для четырех вариантов подключения исследованных образцов; в табл. 1 приведены значения параметров соответствующих ВАХ.

Из рис. 4 и табл. 1 видно, что наименьшим последовательным сопротивлением $\left(R_{s}=0.15 \Omega\right)$ обладает образец с вариантом подключения CSW, в котором ток протекает, минуя мезу. Для этого образца прямое смещение соответствует приложению положительного потенциала к катоду (C), присоединенному к слою $n$ InAs, а отрицательного потенциала - к контакту на подложке (S). Диодный характер BAX, а также наличие отсечки на прямой ветви BAX (рис. 4) указывают на присутствие на пути протекания тока потенциального
Таблица 1. Параметры ВАХ диодов на основе ДГС $p$-InAsSbP/n-InAs $/ n$-InAsSbP для четырех вариантов подключения при комнатной температуре

\begin{tabular}{c|c|c|c|c}
\hline Тип образца & $\mathrm{AC}$ & $\mathrm{ACW}$ & $\mathrm{ASW}$ & $\mathrm{CSW}$ \\
\hline \multicolumn{5}{c}{ Линейное представление } \\
\hline$U_{\text {cutoff, }} \mathrm{V}$ & 0.36 & 0.33 & 0.29 & 0.21 \\
\hline$R_{s}, \Omega$ & 1.46 & 1.36 & 0.32 & 0.15 \\
\hline \multicolumn{5}{c}{ Экспоненциальное представление } \\
\hline$I_{\text {sat }}, \mathrm{A}$ & $2.3 \cdot 10^{-4}$ & $2.1 \cdot 10^{-4}$ & $1.0 \cdot 10^{-4}$ & $2.1 \cdot 10^{-3}$ \\
\hline$\beta$ & 1.94 & 1.76 & 1.37 & 1.57
\end{tabular}

барьера высотой порядка $0.21 \mathrm{eV}$, в 1.7 раз меньшего ширины запрещенной зоны InAs. Это позволяет предположить, что при данном подключении чипа ток протекает, минуя $p-n$-переход, где ширина запрещенной зоны составляет $0.35 \mathrm{eV}$, и отнести указанное выше сопротивление к сопротивлению, возникающему на границе раздела (ГР) узкой $U$-образной части катода, обозначенной на рис. 2, $a$, и слоя $n$-InAs. Отметим, что при допущении о наличии выпрямляющих свойств у ГР слоя $n$-InAsSbP и подложки $n^{+}$-InAs, ограничение тока должно было бы наблюдаться при прямом смещении до $\sim 200 \mathrm{mV}$ [18]. В нашем эксперименте такого ограничения не наблюдалось, поэтому диодный характер ВАХ образца типа CSW связан, вероятнее всего, с барьером на ГР между AO $n$-InAs и слоем $n$-InAsSbP.

Наибольшим последовательным сопротивлением в нашей серии экспериментов обладала структура с удаленной подложкой, в которой оба контакта были расположены на тыльной (эпитаксиальной) стороне чипа $\left(R_{s}^{\mathrm{AC}}=1.46 \Omega\right) \quad($ рис. $3, b, c)$. Исходя из геометрии образца, можно с уверенностью утверждать, что указанное сопротивление формируется не только за счет ГР металл-полупроводник, упомянутой выше, но и за счет протяженного латерального (рис. 3 - горизонтального) участка полупроводника между краями анода и катода. Это согласуется с тем, что ранее в подобной структуре, но с большим расстоянием от мезы до края катода, $R_{s}^{\mathrm{AC}}$ составляла почти в два раза большую величину $(2.7 \Omega,[19])$. В пользу утверждения о преобладании латерального сопротивления служат также и полученные нами ИК изображения и распределение интенсивности электролюминесценции (ЭЛ) вдоль поверхности диода, показывающие локализацию протекания тока при больших его значениях $(I>8 \mathrm{~mA})$ в областях, максимально приближенных к $U$-образному катоду. Иными словами, ИК изображение светящейся области диода начинает повторять контуры катода, т. е. становится серповидным (верхняя вставка на рис. 4). Подобный характер латерального распределения ЭЛ/плотности тока не типичен для диодов, выполненных на основе InAs и близких 

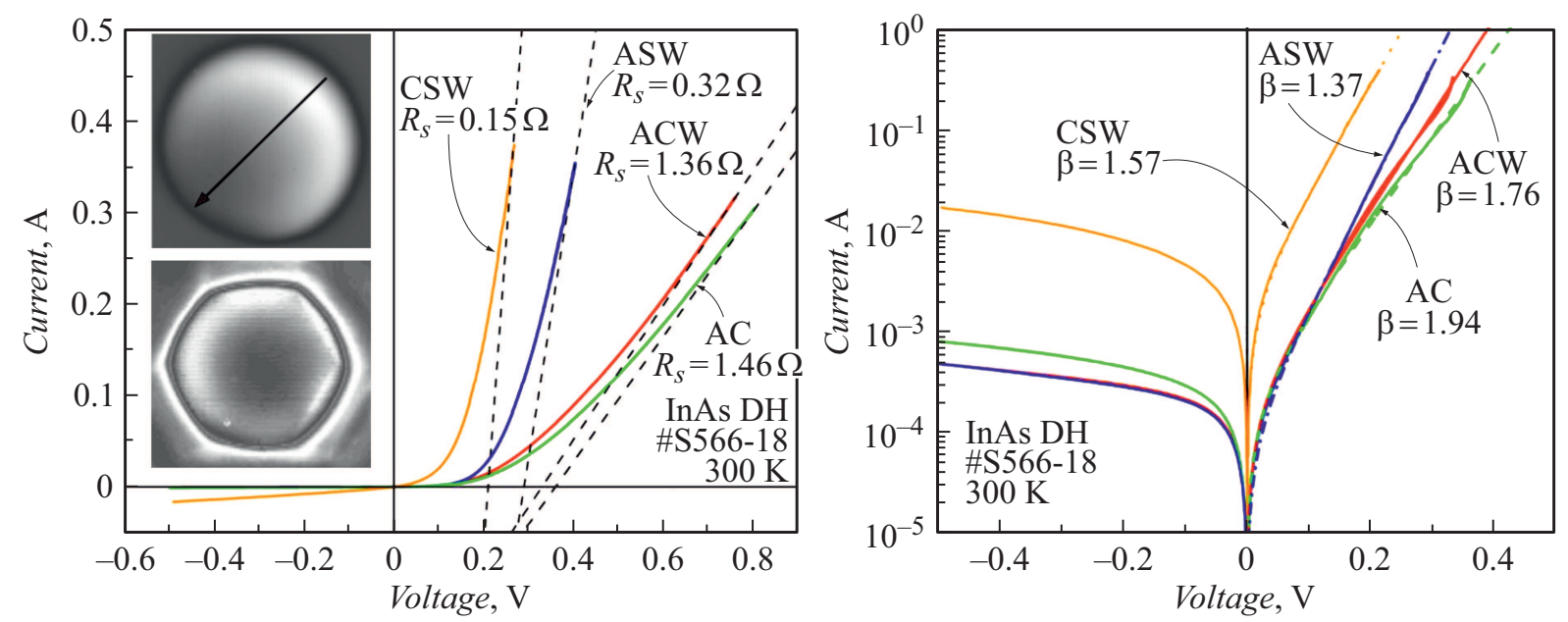

Рис. 4. BAX образцов при температуре $300 \mathrm{~K}$ в линейном (слева) и логарифмическом (справа) масштабах. Штриховыми линиями показаны аппроксимирующие функции: слева - вида (2), справа - вида (1) при значениях параметров, приведенных в табл. 1. На вставках: ИК изображение образца без подложки при токе $9.6 \mathrm{~mA}$ (АС, вверху, черной стрелкой показано направление симметричного сечения чипа); ИК изображение чипа с окном в подложке (ACW, внизу).

к нему по составу твердых растворов в конструкции флип-чип с широкими анодами, для которых во всех ранее опубликованных работах указанное распределение было равномерным (см., например, [20,21]). Локализация плотности тока во флип-чип диодах наблюдалась ранее только для СД на основе InGaAsSb, выращенном на слабо проводящей подложке $p$-GaSb, с которой был сопряжен $U$-образный анод [22]. Неравномерность распределения плотности тока по площади диода является одной из причин искажения вида ВАХ, при этом, как и в случае диодов с точечным контактом [5], сгущение линий тока приводит к увеличению эффективного значения фактора идеальности, в нашем случае до максимального значения $\beta=1.94$.

В образце с подложкой, в которой было сделано глухое отверстие („окно“) (рис. 3, $c$, тип подключения $\mathrm{ACW}$, ИК изображение и распределение ЭЛ при аналогичном вышеописанному подсоединении проводников радиально симметричны в латеральной плоскости в соответствии с геометрией „окна““ в высокопроводящей подложке (нижняя вставка на рис. 4). Центральная область мезы равноудалена от высокопроводящих областей $n^{+}$-InAs, поэтому плотность тока и соответственно интенсивность ЭЛ в центре мезы минимальны. Последовательное сопротивление этого образца (рис. 3,c) несколько меньше, чем для образца без подложки (рис. $3, b)$ и составляет $R_{s}^{\mathrm{ACW}}=1.36 \Omega\left(\beta_{\mathrm{ACW}}=1.76\right)$.

Уменьшение влияния латерального токопрохождения, например, путем подачи смещения на анод и подложку (подключение ASW, рис. 3,d) еще более снижает величины последовательного сопротивления и фактора идеальности соответственно до $R_{s}^{\mathrm{ASW}}=0.32 \Omega$, $\beta_{\mathrm{ASW}}=1.37$.

Полученная совокупность данных позволила нам составить примерную эквивалентную электрическую схе- му двойных гетероструктур InAsSbP/InAs, содержащих контакты и подложку $n^{+}-$InAs (рис. 5) и провести оценку электрических характеристик отдельных ее элементов (табл. 2). Как видно из табл. 2, для образцов АС и $\mathrm{ACW}$ латеральное сопротивление примерно втрое выше вертикального, что и является причиной наблюдаемой неравномерности распределения плотности тока. Высокое латеральное сопротивление структуры приводит к снижению эффективности сбора фототока [15]; это негативно скажется на характеристиках ТФВП, выполненных на основе таких структур.

Из рис. 5 видно, что в образцах с подключением типа АC и $\mathrm{ACW}$ ток от анода до катода после прохождения $p-n$-перехода имеет два пути: а) через АО $n$-InAs (путь 4-5); б) через ГР $n$-InAs/n-InAsSbP и слой $n$-InAsSbP, причем барьер $n$-InAs/ $n$-InAsSbP пересекается сначала в прямом направлении, а затем в обратном (путь 6-7-6-5). С учетом этого, а также диодного характера BAX перехода $n$-InAs $/ n$-InAsSbP, можно предположить, что основная часть тока идет в AO $n$-InAs. При подключении по типу ASW ток после прохождения через $p-n$-переход протекает по двум параллельным участкам: через $\mathrm{AO}$ (участок 4-6-8-9) и через слой $n$-InAsSbP (участок 6-7-8-9). Изотипный переход $n$ $\mathrm{InAs} / n$-InAsSbP (позиция 6 на рис. 5) в этом случае несколько улучшает растекание тока. Стоит отметить, что для образца ASW, в котором ток проходил последовательно через два барьера, напряжение отсечки было заметно ниже, чем для образцов $\mathrm{AC}$ и $\mathrm{ACW}$, в которых на пути протекания тока был только один барьер $p-n$ переход (табл. 1). Полученные результаты не согласуются с данными работы [23], в которой ВАХ диодов на основе двойных ГС $p$-InAsSbP/n-InAs $/ n$-InAsSbP $/ n^{+}$InAs характеризовались более высоким напряжением прямого смещения по сравнению с диодами на осно- 
Таблица 2. Сопротивления областей ДГС $p$-InAsSbP/n-InAs/n-InAsSbP

\begin{tabular}{l|c|l}
\hline \multicolumn{1}{c|}{ Элемент схемы } & № позиции на рис. 5 & \multicolumn{1}{c}{ Величина сопротивления } \\
\hline $\begin{array}{l}\text { Переходное сопротивление между анодом } \\
\text { и слоем } p \text {-InAsSbP }\end{array}$ & 1 & $\begin{array}{l}R_{a} \sim(0.13-0.15) \Omega, \\
R_{a} S_{a} \sim(0.9-1.0) \cdot 10^{-4} \Omega \cdot \mathrm{cm}^{2}\end{array}$ \\
\hline $\begin{array}{l}\text { Вертикальное сопротивление слоя } p \text {-InAsSbP } \\
\text { Переходное сопротивление АО } n \text {-InAs }\end{array}$ & 2 & $\begin{array}{l}R_{p} \sim(0.017-0.045) \Omega, \\
\rho_{p} \sim(0.03-0.08) \Omega \cdot \mathrm{cm}\end{array}$ \\
\hline $\begin{array}{l}\text { п прилегающей к ней части катода } \\
\text { Суммарное вертикальное сопротивление для образца ASW }\end{array}$ & $\begin{array}{l}R_{c} \sim 0.15 \Omega, \\
R_{c} S_{c} \sim 0.37 \cdot 10^{-4} \Omega \cdot \mathrm{cm}^{2}\end{array}$ \\
\hline Суммарное вертикальное сопротивление для образца ACW & $1,2,9$ & $R_{a}+R_{p} \sim(0.15-0.17) \Omega$ \\
\hline Латеральное сопротивление образца АСW & $1,2,5$ & $R_{a}+R_{p}+R_{c} \sim(0.30-0.32) \Omega$ \\
\hline Суммарное вертикальное сопротивление для образца AC & 4,7 & $R_{\ell} \sim(1.01-1.06) \Omega$ \\
\hline Латеральное сопротивление образца АС & $1,2,5$ & $R_{a}+R_{p}+R_{c} \sim(0.30-0.32) \Omega$ \\
\hline
\end{tabular}

Пр и ме ч ан и е. $S_{a}-$ площадь анода, $S_{c}$ - площадь прилегающей к слою $n$-InAs части катода.

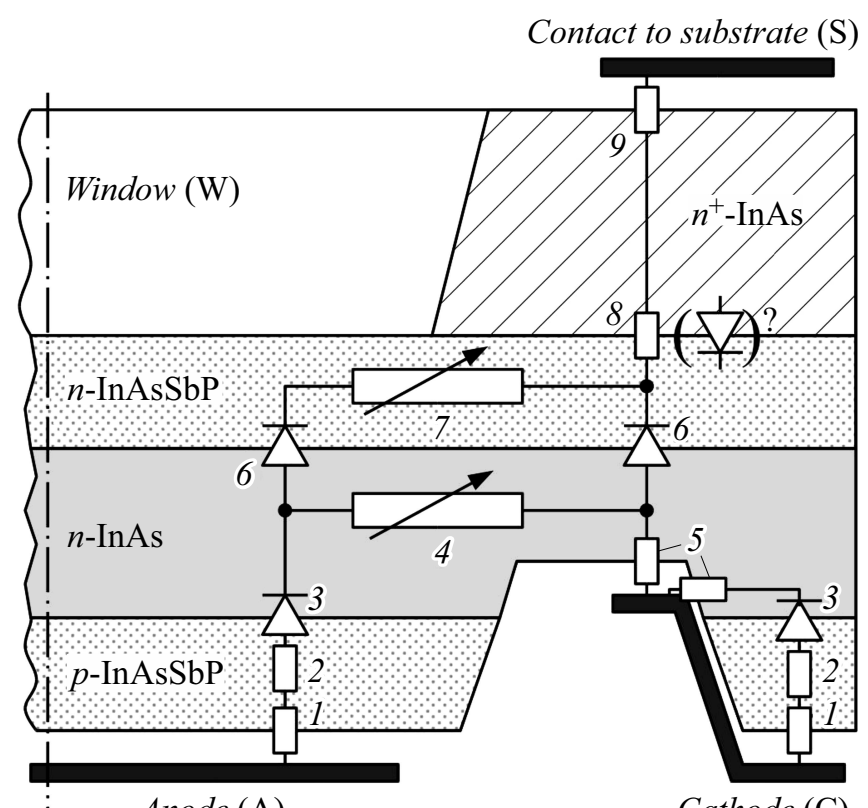

Anode (A)
Cathode $(\mathrm{C})$

Рис. 5. Упрощенная эквивалентная схема флип-чип диода на основе ДГС $p$-InAsSbP $/ n$-InAs $/ n$-InAsSbP. Цифрами на схеме обозначены: 1 - переходное сопротивление между анодом и слоем $p$-InAsSbP, 2 - вертикальное сопротивление слоя $p$-InAsSbP, $3-p-n$-переход $p$-InAsSbP/n-InAs, 4 - латеральное сопротивление слоя $n$-InAs, 5 - переходное сопротивление между слоем $n$-InAs и катодом, 6 - изотипный гетеропереход $n$-InAs $/ n$-InAsSbP, 7 - латеральное сопротивление слоя $n$-InAsSbP, 8 - изотипный гетеропереход $n$-InAsSbP $/ n^{+}$InAs, 9 - переходное сопротивление между подложкой $n^{+}$InAs и контактом к ней. Штрихпунктирной линией показана ось симметрии мезы.

ве одиночных ГС $p$-InAsSbP/n-InAs $/ n^{+}$-InAs. Согласно эквивалентной схеме диода (рис. 5) и данным [23], для образца ASW естественно ожидать более высокого

напряжения отсечки, чем для образцов $\mathrm{AC}$ и $\mathrm{ACW}$. Очевидно, что особенности многобарьерных диодных структур применительно к ТФВП требуют дополнительного исследования, которое будет проведено нами в отдельной работе.

Из табл. 1 и 2 видно, что для образца ASW латеральное сопротивление составляет $0.15-0.17 \Omega$, т.е. примерно половину величины последовательного сопротивления $\left(R_{s}^{\mathrm{ASW}}=0.32 \Omega\right)$, поэтому можно ожидать высокой эффективности сбора фототока в ТФВП такой конфигурации. При травлении мезы на глубину, превышающую толщину эпитаксиальной части структуры, оба омических контакта для ТФВП типа ASW можно формировать на эпитаксиальной стороне. Удаление части подложки над мезой приводит к существенному повышению токовой чувствительности в коротковолновой части спектра [14], что делает структуры с „окном“ в высокопроводящей подложке (типа ASW) наиболее перспективными для ТФВП.

\section{Заключение}

Таким образом, установлено, что на границе раздела между нелегированными слоями $n$-InAs и nInAsSbP имеется изотипный потенциальный барьер высотой $\sim 0.21 \mathrm{eV}(300 \mathrm{~K})$, обладающий выпрямляющими свойствами, причем прямое смещение соответствует приложению положительного потенциала к $n$-InAs и отрицательного к $n$-InAsSbP.

Во флип-чип диодах на основе двойных гетероструктур $p$-InAsSbP/n-InAs/n-InAsSbP с катодом, сопряженным с активной областью $n$-InAs, имеет место локализация прохождения тока в областях, примыкающих к катоду, из-за того что латеральное сопротивление слоев $n$-InAs и $n$-InAsSbP много больше сопротивления омических контактов. 
Полное удаление сильнолегированной подложки $n^{+}$InAs в структурах $p$-InAsSbP $/ n$-InAs $/ n$-InAsSbP $/ n^{+}$-InAs в области, примыкающей к мезе (т.е. создание „окна“ в $n^{+}$-InAs), создает условия для радиально-симметричного пространственного токопрохождения, что обеспечивает одновременно и получение широкого спектрального оклика, и повышенного по сравнению с другими вариантами конструкций коэффициента сбора фототока.

\section{Благодарность}

Авторы выражают благодарность Н.Д. Ильинской, А.А. Усиковой, Н.М. Стусю, М.А. Ременному и С.А. Карандашеву за помощь в работе, а также сотрудникам ЦКП „Элементная база радиофотоники и наноэлектроники: технология, диагностика, метрология“ за исследования ближнего поля собственной эмиссии ФД.

\section{Финансирование работы}

Работа, выполненная в ООО „ИоффеЛЕД“, поддержана проектом ФЦП „Разработка фоточувствительных элементов большой размерности для спектральных областей $2.5-3.5 ; 2.5-4.5 ; 2.5-5.5$ мкм на основе диодных гетероструктур из InAs и твердых растворов InAsSbP“ (код контракта 14.576.21.0104, ID: RFMEFI57618X0104).

\section{Конфликт интересов}

Авторы заявляют, что у них нет конфликта интересов.

\section{Список литературы}

[1] Gladilin A.A., Gulyamova E.S., Danilov V.P., Ilichev N.N., Kalinushkin V.P., Odin I.N., Pashinin P.P., Rezvanov R.R., Sidorin A.V., Studenikin M.I., Chapnin V.A., Chukich M.V. // Quant. Electron. 2016. Vol. 46. N 6. P. 545. http://dx.doi.org/10.1070/QEL1

[2] Гаврилов Г.А., Капралов А.Ф., Муратиков К.Л., Панютин Е.А., Сотников А.В., Сотникова Г.Ю., Шарофидинов Ш.Ш. // Письма в ЖТФ. 2018. Т. 44. Вып. 16. С. 11-19.

[3] Fioravanti V., Brandhoff L., van den Driesche S., Breiteneder H., Kitzwögerer M., Hafner C., Vellekoop M.J. // Sensors. 2016. Vol. 16. N 10. P. 16. DOI: $10.3390 / \mathrm{s} 161016$

[4] Köhring M., Böttger S., Willer U., Schade W. // Sensors (Basel). 2015. Vol. 15. N 5. PMC4481913.

[5] Карандашев С.А., Матвеев Б.А., Ременный М.А. // ФТП. 2019. Т. 53. Вып. 2. С. 147-157.

[6] Zymelka D., Matveev B., Aleksandrov S., Sotnikova G., Gavrilov G., Saadaoui M. // IOP J. Flexible and Printed Electron. 2017. Vol. 2. P. 045006.

DOI: $10.1088 / 2058-8585 / \mathrm{aa} 900 \mathrm{a}$

[7] Zhou X., Meng X., Krysa A.B., Willmott J.R., Ng J.S., Tan C.H. // IEEE Sens. J. 2015. Vol. 15. N 10. P. 5555-5560.

[8] Mauk M.G., Andreev V.M. // Semicond. Sci. Technol. 2003. Vol. 18. N 5. P. S191-S201.

[9] Datas A. // Solar Energy Mater. Solar Cells. 2015. Vol. 134. N 1. P. 275-290.
[10] Krier A., Yin M., Marshall A.R.J., Krier S.E. // J. Electron. Mater. 2016. ttp://dx.doi.org/10.1007/s11664-016-4373-0

[11] Матвеев Б.А., Ратушный В.И., Рыбальченко А.Ю. // ЖТФ. 2019. Т. 89. Вып. 8. С. 1239-1243.

[12] Астахова А.П., Головин А.С., Ильинская Н.Д., Калинина К.В., Кижсаев С.С., Серебренникова О.Ю., Стоянов Н.Д., Horvath Zs.J., Яковлев Ю.П. // ФТП. 2010. Т. 44. Вып. 2. С. 278-284.

[13] Геворкян В.А., Арутюнян В.М., Гамбарян К.М., Аракелян А.О., Андреев И.А., Голубев Л.В., Яковлев Ю.П. // ЖТФ. 2007. Т. 77. Вып. 3. С. 49-54.

[14] Ременный М.А., Карандашев С.А., Климов А.А., Майоров Н.С., Матвеев Б.А., Петров А.С. Труды XXV юбилейной Междунар. научно-технической конф. по фотоэлектронике и приборам ночного видения в 2-х томах. Т. 1 . М.: Изд-во „ОФСЕТ МОСКВА“, 2018. С. 77-79.

[15] Ильинская Н.Д., Закгейм А.Л., Карандашев С.А., Матвеев Б.А., Ратушный В.И., Ременный М.А., Рыбальченко А.Ю., Стусь Н.М., Черняков А.Е. // ФТП. 2012. Т. 46. Вып. 5. С. 708-713.

[16] Закгейм А.Л., Ильинская Н.Д., Карандашев С.А., Лавров А.А., Матвеев Б.А., Ременный М.А., Стусь Н.М., Усикова А.А., Черняков А.Е. // ФТП. 2017. Т. 51. Вып. 2. C. 269-275.

[17] База данных New Semiconductor Materials. Biology systems. http://www.matprop.ru/

[18] Романов В.В., Иванов Э.В., Моисеев К.Д. // ФТТ. 2018. Т. 60. Вып. 3. С. 585-590.

[19] Aidaraliev M., Zotova N.V., Ilinskaya N.D., Karandashev S.A., Matveev B.A., Remennyi M.A., Stus' N.M., Talalakin G.N. // Semicond. Sci. Technol. 2003. Vol. 18. P. $269-272$

[20] Зотова Н.В., Ильинская Н.Д., Карандашёв С.А., Матвеев Б.А., Ременный М.А., Стусь Н.М. // ФТП. 2008. Т. 42. Вып. 6. С. 641-657.

[21] Ильинская Н.Д., Карандашёв С.А., Карпухина Н.Г., Лавров А.А., Матвеев Б.А., Ременный М.А., Стусь Н.М., Усикова А.А. // Прикладная физика. 2014. № 6. С. 47-51.

[22] Закгейм А.Л., Ильинская Н.Д., Карандашев С.А., Матвеев Б.А., Ременный М.А., Черняков А.Е., Шленский А.А. // ФТП. 2009. Т. 43. Вып. 5. С. 689-694.

[23] Matveev B.A., Ankudinov A.V., Zotova N.V., Karandashev S.A., L'vova T.V., Remennyy M.A., Rybal'chenko A.Yu., Stus' N.M. // Proc. SPIE 7597. Physics and Simulation of Optoelectronic Devices XVIII, 75970G (25 February 2010). 